\title{
Sensitivity analysis of demand-side management impact on Abu-Dhabi's electricity consumption
}

\author{
Luiz Friedrich*, Afshin Afshari \\ Masdar Insitute of Science and Technology (MIST), Abu Dhabi,UAE
}

\begin{abstract}
The difficulty to accurately assess the impact of energy efficiency retrofits and the impact of energy efficiency policies is a widely recognized barrier to the wider deployment of Demand-Side Management (DSM). The task is complicated by the dynamic nature and coupled interaction of the sub-system and the high correlation with weather and other perturbations. A regression-based model of the load is estimated using measured data from the pre-DSM period for the city of Abu Dhabi, UAE, and is then used to generate proxies representing the main characteristics of the Abu Dhabi urban buildings which impact the cooling load. The sensitivity analysis to variations of the most important proxies that drive cooling load was performed, and the impact assessed for the aggregate urban area of Abu Dhabi municipality. Well targeted DSM interventions can achieve an average $20 \%$ improvement of the cooling process in Abu-Dhabi. The present study estimates that an emirate-wide program could result in a peak load relief of $6.6 \%$ and annual energy conservation of $9.2 \%$ (respectively $450 \mathrm{MW}$ and 3,600 GWh based on 2010 emirate-wide electricity use statistics).
\end{abstract}

Keywords: Urban energy modeling, sensitivity analysis, energy efficiency, demand-side management

\section{Introduction}

Lying in the southeast of the Arabian Peninsula, the United Arab Emirates (UAE) has been reported as the world's worst ecological footprint per person by the World Wildlife Fund's Living Planet Report of 2008 [1], experiencing only minor improvements by the publication of the 2012 report [2]. This report called for proper planning and policy-making in order to rein in the country's environmental impact, in an era of increasing international pressure towards mitigation of pollutants and green house gases (GHG) emissions. The high temperatures and humid climate of the region during most of the year has a significant impact on the role of cooling load and in the overall per capita electricity consumption.

One of the most constructive and cost-effective ways for reducing green house gases emission and achieving international targets, is by promoting demand-side energy efficiency. Demand side management of buildings' indoor air conditioning, can be approached from several angles: improvements of the cooling plants and chilled water or cool air distribution networks, building envelope insulation and solar gain reduction, day-light versus artificial light optimization and finally savings and peak load reductions via advanced controls.

The first step in this direction is the provision of standard method for accounting for the overall energy savings, as well as understanding the impacts of energy efficiency measures in an aggregated urban area. Estimating savings are a notoriously diffcult task, given the complexity and dynamics of the systems involved, the uncertain role of energy prices, lack of information on driving variables, unpredictability of end-user behavior and weather variability. The objective of this study is to identify the electricity consumption sensitivity, for an aggregate urban area, to some parameters that reflect the overall buildings' characteristics that can be changed by buildings' retrofits and targeted demand-side energy

\footnotetext{
* Manuscript received July 5, 2013; revised October 8, 2013.

Corresponding author: Luiz Friedrich; E-mail address: lafriedrich@masdar.ac.ae.
} 
efficiency measures.

\section{Problem Definition}

It is estimated that $40 \%$ of the total annual electrical consumption and $61 \%$ of the peak summer day consumption in the UAE could be traced back to air-conditioning [3]. Given the generally unsatisfactory level of thermal insulation in existing buildings and the extreme weather conditions in the long summer season, electricity load in the UAE and in most neighboring countries is highly correlated with weather for most part of the year. This fact designates air-conditioning load as the primary target of any systematic energy efficiency drive. It is essential to distinguish between sensible cooling (energy demand directly responsible for keeping the building's indoor dry bulb temperature within a prescribed range) from latent cooling (energy required to dehumidify the air), as well as the overall impact of wind and changes in buildings time constants (heat transfer delays).

Increasing fossil fuel prices and reduced infrastructure investment availability are prompting energy sector planners to reduce and optimize energy generation requirements and enhance the utilization of the existing electricity infrastructure. Energy generation, transmission and distribution infrastructures have to be sized to supply the annual peak load, even if that peak occurs only during a short period and is far higher than the average system utilization rate.

The main objective of this study was to identify the sensitivity of the load to some parameters representing the average building characteristics, based on a mathematical model of electricity consumption, which enables the assessment of the impact to some of the most common Demand-side Management (DSM) initiatives, for the aggregate urban area of Abu Dhabi municipality. This study provides an estimate of energy savings that can be used as guideline in order to develop energy-efficiency policies targeting the general residential/retail buildings population, in order to curb energy consumption, peak demand and environmental impact.

\section{Literature Study}

Indoor climate control is responsible for a large fraction of the world's energy consumption. In the United Kingdom, more than $60 \%$ of the energy consumption is used for indoor climate control with large potential of energy savings by energy efficiency [4]. A study for Saudi Arabia, a similar climate as presented here, showed that $15 \%, 19 \%$ and $40 \%$ annual energy can be saved in large, medium and small office buildings through envelope thermal optimization in the hot-humid climate of Riyadh, also for the city of Jeddah, annual energy savings of $8 \%, 12 \%$ and $24 \%$ can be obtained for large, medium, and small offices, respectively [5]. A series of studies targeting energy efficiency on commercial building are available as there are many untapped opportunities in this area [6], [7].

Sensitivity analysis is a valuable tool being used across a wide range of applications in science and engineering. Reference [8] investigated the characteristics of 10 air-conditioned office buildings in subtropical Hong Kong, using building energy simulation in order to assess the sensitivity to potential energy saving programs. Similarly, the sensitivity of the thermal response of three different building kinds was analyzed in [9].

There are two methods for sensitivity analysis applied in the domain of building analysis based on input variation: local and global methods [10]. Local sensitivity analysis can be compared to the Monte Carlo Simulation, which focuses on the effects of uncertain inputs around a point (or base case), whereas global sensitivity analysis is more interested in the influences of uncertain inputs over the whole input space [11]. These methods are used to cover the input space and to analyze the variations to the inputs impacting the output. A comparison of both methods was done in [12].

Another approach more relevant to energy efficiency assessment consists in varying the parameters related to buildings' characteristics, as opposed to weather inputs, and identifying the impact on energy consumption. 12 input parameters were analyzed to identify the sensitivity of energy performance of office buildings in Hong Kong [13]. A similar study for public buildings in Portugal was conducted in 
[14], were parameters as wall and roof structure and materials, window frames, shading system, infiltration, mechanical ventilation, heating, ventilation and air conditioning (HVAC) system, design temperatures and thermostats set-point were tested.

A parametric model of electricity consumption was used in order to test the sensitivity of the electricity consumption to the variation of some parameters representing the buildings characteristics. There are two main classes of methods for predicting and analyzing aggregate urban energy usage [15], the bottom-up and the top-down approach. A comparison of both classes and an analysis of the possible approaches in each category are done in [16]. The traditional bottom-up approach is usually focused on data from surveys and field measurements of the energy consumption and building characteristics, identifying fixed demand per unit floor area or per household and extrapolating the results to infer global urban usage characteristics. This approach usually fails to model the total energy use in buildings and the urban level with sufficient resolution, due to a non-linear relationship between electricity load and floor area. A more precise approach consists of a series of building models representing the overall building stock, individual simulation of each building are aggregated together based on the overall representativity of each building type in the studied area, in order to predict urban energy use [17-19]. Its main weaknesses lie in the high dependency on the precision of the building prototype models, in the collected data of the buildings, in how the individual data is aggregated, and in the assumptions made with regard to changing demographic factors, hours of occupancy, indoor climate control system in use etc. [20]. The work described in [21] shows the application of an urban energy model based on individual representative buildings combined into "building clusters" for specific districts of Osaka city, Japan, considering different energy efficiency and energy saving measures.

Bottom-up models work at a disaggregated level, and thus the detail, precision and size of the underlying building database directly influences the final result of the model [22]. Other phenomena such as the Urban Heat Island effect cannot be properly accounted for and estimated, since in practice the overall urban energy consumption is different from the sum of all its constituent building loads due to the urban micro climate which impacts cooling and heating energy requirements [23]. Given the complex dynamics of the system, the non-linearity and coupling of sub-systems and the high correlation with weather and other random perturbations, the bottom up approach has many limitations when applied to urban/district energy models.

As opposed to the bottom-up approach, the top-down approach consists in utilizing high level data, such as the approximate aggregate energy consumption, macroeconomic data, population growth, buildings construction/demolition rate and meteorological data to define overall urban level consumption characteristics and trends. The parameters of the resulting models are either sensitivity coefficients or lumped physical properties. For the top-down approach, contributions can be broadly classified in three main categories [24]: time series models, Artificial Neural Networks (ANN) and regression-based approaches.

Time series models are best suited for capturing the time dependence of the load, seasonal effects (summer, winter), day-of-the-week (working day, non-working day), calendar holidays, different hours of the day and trends in general [25]. Artificial Neural Networks (ANN) methods, often classified as "blackbox" type models, automatically interpolate among the electricity load and hour, day-of-week, day-ofyear and weather data in a training data set based on a predefined model structure. The presumed advantage is the ability to learn complex and non-linear relationships that are difficult to model with conventional techniques [26-29]. Due to the nature of the ANN methods, the coefficients (weights) cannot be matched with the underlying physical phenomena, therefore the marginal impact of each input variable is not clear from the model coefficients and is not particularly useful for the purpose of the work here described.

Regression models utilize the strong correlation of load with relevant factors such as weather, hour-ofthe-day and day-of-the-week. A comparison between six modeling techniques was done for short term urban level energy forecast [30], the regression model yielded the best results for up to one day ahead, being only outperformed by one of the methods (exponential smoothing filter with autoregressive 
component) for one to two days ahead forecast. In [31], a linear regression model was used to estimate the elasticity of GDP, price and GDP per capita for the domestic and non-domestic Italy's energy consumption, and comparing it with available projections.

Regression analysis was the method chosen in this study for combining and pondering the different effects, due to its relatively low computational cost and broad range of application. This approach also produces easily interpretable sensitivity coefficients for the different drivers of the load, facilitating the analysis of each component individually, and maintaining the physical significance of the coefficients.

\section{Method}

The work here described was based on a mid-term (one week to a year ahead) low complexity linear model (with some light non-linearity explored) of hourly electricity load for Abu Dhabi described in [32]. Abu-Dhabi's load is mostly residential and commercial. The industrial \& agricultural load represented less than $12 \%$ of the total load in the Emirate [33]. A subset of substations, which are all within the municipality of Abu-Dhabi, was selected in order to when aggregated, constitute a better proxy for the buildings load (residential, office/institutional and retail). Hourly electricity consumption data from all 29 low-voltage substations of $11 \mathrm{kV}, 22 \mathrm{kV}$ and $33 \mathrm{kV}$ that directly supply street transformers serving final customers was used in a linear regression model of electricity consumption, relying on substation-level hourly electricity data measured by the SCADA (supervisory control and data acquisition) system of Abu-Dhabi emirate's utility as well as robust hourly weather data (including solar irradiance) monitored by Masdar City's comprehensive weather station for the calendar year 2010 (January 1st - December 31st) and the first half of 2011 (January 1st - June 30th), was used in order to segregate the weather dependent from the non-weather dependent portion of the load.

The model uses a technique also referred to as inverse modeling, to be distinguished from load forecasting, since it is performed off-line (ex post) on historical time-series data (typically one year or more), with the objective of establishing a baseline model of electricity consumption for measurement and verification of demand-side energy efficiency interventions, and enabling the model parameters to represent the sensitivity for some of the load-affecting components, in order to predict overall impact of some planned DSM interventions on load.

The hourly electricity consumption data for 2010 was used in the parameter estimation phase, with adjusted R-squared reaching 0.9931 . The first half of 2011 data was used for testing the model prediction capabilities, resulting in a RMSE of $35.63 \mathrm{MW}$, equivalent to $1.84 \%$ of the 2010 's peak load, and a MAPE of $2.64 \%$.

Based on the model, the weather dependent load accounts for approximately $30 \%$ of the overall electricity usage, while during the peak summer hour this value reaches $49 \%$ of the total electricity load. From the weather dependent fraction of the load, which can be considered mostly cooling load, proxies ${ }^{\mathrm{b}}$ that represent the sensible cooling load, latent cooling load, impact of wind and changes in the buildings time constant (heat transfer delays) were derived. The sensitivity to each of these proxies was studied in order to assess the impact that such changes would produce in the aggregate urban level electricity consumption characteristics.

\section{Sensitivity Analysis}

Let $\hat{Y}$ represent the hourly energy consumption, the model used is shown in (1), where $\hat{Y}_{1}$ represents the non-weather dependent fraction of the load and $\hat{Y}_{2}$ the weather dependent for each hour. In (2), $\eta$ is the coefficient for each proxy, while $X_{2}$ is the measured/derived proxy value. Equation (3) shows the

\footnotetext{
${ }^{\mathrm{b}}$ Proxy Variable: an indicator used to account for a variable in a model which simply has no fully observable/measurable counterpart [34].
} 
coefficient of each proxy, where $\theta$ represents the sensible cooling, $\gamma$ the latent cooling, $\omega$ wind component and $\tau$ the time constant of the buildings, while (4) shows the breakdown of $X_{2}$, similarly to the structure of $\eta$.

$$
\begin{aligned}
& \hat{Y}=\hat{Y}_{1}+\hat{Y}_{2} \\
& \hat{Y}_{2}=\eta X_{2} \\
& \eta=\left[\begin{array}{llll}
\hat{\eta}_{\theta} & \hat{\eta}_{\gamma} & \hat{\eta}_{\omega} & \hat{\eta}_{\tau}
\end{array}\right] \\
& X_{2}=\left[\begin{array}{llll}
\theta & \gamma & \omega & \tau
\end{array}\right]^{\prime}
\end{aligned}
$$

In order to estimate the impact of planned DSM interventions on annual energy use and peak demand, we have analyzed the sensitivity of the load to the weather parameters. By varying each of these coefficients that represents a certain physical characteristic of the average building in Abu-Dhabi, and estimating the energy consumption using the new coefficient, the forecasted electricity consumption can be compared to the measured consumption and the differences be identified. For instance, $\eta_{\theta}$ is a function of the efficiency of the sensible cooling systems, the level of insulation of the external walls and, to a smaller extent, the solar gain of the buildings. Understandably, the load shows the highest sensitivity to this parameter, especially when it comes to annual energy. Let $E$ represent the annual energy consumption and $P$ the peak summer load, an average $10 \%$ decrease of $\eta_{\theta}$ throughout the city (i.e. a $10 \%$ improvement of the sensible cooling equipment or, equivalently, a $10 \%$ reduction in the building envelope's U-value) is expected to reduce the overall energy consumption by $4 \%$ (5). It will also reduce the peak summer load by $2.5 \%$ (6).

$$
\begin{aligned}
& P_{\theta}=\frac{d E}{E} / \frac{d \eta_{\theta}}{\eta_{\theta}}=0.40 \\
& \mu_{\theta}=\frac{d P}{P} / \frac{d \eta_{\theta}}{\eta_{\theta}}=0.25
\end{aligned}
$$

The load is also sensitive to the latent cooling parameter $\eta_{\gamma} . \eta_{\gamma}$ is a proxy for the average efficiency of the latent cooling systems in Abu-Dhabi. Although generally less significant than $\eta_{\theta}, \eta_{\gamma}$ has a higher impact on peak load than on overall energy. An average $10 \%$ decrease of $\eta_{\gamma}$ is expected to reduce energy consumption by $0.6 \%$ (7) and the peak load by $0.8 \%$ (8).

$$
\begin{aligned}
& \rho_{\gamma}=\frac{d E}{E} / \frac{d \eta_{\gamma}}{\eta_{\gamma}}=0.06 \\
& \mu_{\gamma}=\frac{d P}{P} / \frac{d \eta_{\gamma}}{\eta_{\gamma}}=0.08
\end{aligned}
$$

Although the impact of $\eta_{\gamma}$ is not as significant as that of $\eta_{\theta}$, improving the efficiency of the latent cooling process is relatively straightforward, e.g. via addition of heat recovery wheels in air-handling units or CO2-based control of the fresh air intake.

$\eta_{\omega}$ has a negative impact on load, because wind cools down the building naturally and reduces the need for mechanical cooling. $\eta_{\omega}$ is a proxy for the surface convection heat transfer coefficient of buildings. The sensitivity of the load to $\eta_{\omega}$ is more difficult to interpret.

A $10 \%$ increase in the absolute value of $\eta_{\omega}$ (i.e. a $10 \%$ decrease of the algebraic value) results in a 
$0.2 \%$ (9) decrease of the peak load, while annual energy use is almost unchanged (10).

$$
\begin{aligned}
& \rho_{\omega}=\frac{d E}{E} / \frac{d \eta_{\omega}}{\eta_{\omega}}=-0.004 \\
& \mu_{\omega}=\frac{d P}{P} / \frac{d \eta_{\omega}}{\eta_{\omega}}=0.02
\end{aligned}
$$

Although the convection heat transfer coefficient, and consequently $\eta_{\omega}$, cannot be easily modified through a DSM intervention in an existing city, this result is significant because it demonstrates and quantifies, the impact of natural ventilation on urban cooling energy demand. In the context of new city design, it can contribute to putting a value on the master-planning strategies aimed at enhancing the urban microclimate and in particular facilitating the flow of the wind, e.g, aligning the main road axes with the direction of the prevailing winds or using wind towers to capture overflowing wind and bring it into contact with building surfaces. That being said, the impact is not huge and even a $50 \%$ increase in the absolute value of the parameter, which may require drastic and presumably unproven urban design choices, reduces peak load by only $1 \%$. It is important to note that this result is partly due to the generally low wind speed values in Abu-Dhabi-the average annual wind speed does not exceed $4 \mathrm{~m} / \mathrm{s}$. It is even less than that during the hot summer months. The existence of heat islands in downtown is probably also a detrimental factor. In a more windy region, the impact would be greater, easily by a factor 2 or 3 .

Sensitivity to building time constant $\eta_{\tau}$ (only in the residential/commercial), is not apparent at aggregate system level.

\section{Conclusions}

In this study, the sensitivity analysis to variations of the most important proxies that drive cooling load was performed, and the impact on electricity consumption assessed for the aggregate urban area of Abu Dhabi municipality buildings (residential, office/institutional and retail), based on a linear regression model of electricity consumption.

The application of this knowledge can be used to target efforts, improving planning and policy making for the general urban environment, in order to achieve the higher impacts reducing overall energy consumption and summer peak demand, resulting in lower operational costs and GHGs emissions. This result may as well aid the development of future building codes.

The proxy representing the efficiency of the sensible cooling systems, the level of insulation of the external walls and the impact of solar gain, was proved to have the highest impact in the studied area. Improving such building characteristics in the order of $10 \%$ is expected to reduce the overall energy consumption by $4 \%$ and the summer peak load by $2.5 \%$.

Some of our experimental and theoretical investigations indicate that achieving an average $20 \%$ improvement of the cooling process in Abu-Dhabi via well targeted DSM interventions (building envelope enhancement, chiller/Air Handling Unit upgrade/maintenance, re-commissioning, advanced control \& monitoring, etc.) is not beyond reach in the short to mid-term. The present study estimates that such a city-wide program could result in a peak load relief of $6.6 \%$ and annual energy conservation of 9.2\% (respectively 450MW and 3,600 GWh based on 2010 emirate-wide electricity use statistics).

For future research, a more dynamic modeling approach (transfer function, state-space) might be able to increase the model's accuracy, better utilizing the info mation presented in the data, while producing physically significant lumped parameters-conductive/convective/solar gain of the buildings, chiller efficiency, etc. - which can be used for advanced sensitivity analysis and more specific what-if scenario analysis. 


\section{References}

[1] WWF, "Living Planet Report 2008," 2008.

[2] WWF, "Living Planet Report 2012," 2012.

[3] Ali M. T., Mokhtar M., Chiesa M., Armstrong P., "A cooling change-point model of community-aggregate electrical load," Energy and Buildings, vol. 43, no. 1, pp. 28-37, 2011.

[4] Tham K., "Conserving energy without sacrificing thermal comfort," Building and Environment, vol. 28, no. 3, pp. 287-299, 1993.

[5] Al-Homoud M. S., "Optimum thermal design of office buildings," International Journal of Energy Research, vol. 21, no. 10, pp. 941-957, 1997.

[6] Lam J. C., Li D. H., "Electricity consumption characteristics in shopping malls in subtropical climates," Energy Conversion and Management, vol. 44, no. 9, pp. 1391-1398, 2003.

[7] Yu P. C., Chow W., "Energy use in commercial buildings in Hong Kong," Applied Energy, vol. 69, no. 4, pp. $243-255,2001$.

[8] Lam J. C., Wan K. K., Yang L., "Sensitivity analysis and energy conservation measures implications," Energy Conversion and Management, vol. 49, no. 11, pp. 3170-3177, 2008.

[9] Buchberg H., "Sensitivity of the thermal response of buildings to perturbations in the climate," Building Science, vol. 4, no. 1, pp. 43-61, 1969.

[10] Saltelli A., Ratto M., Tarantola S., Campolongo F., "Update 1 of: Sensitivity Analysis for Chemical Models," Chemical Reviews, vol. 112, no. 5, pp. PR1-PR21, 2012.

[11] Heiselberg P., Brohus H., Hesselholt A., Rasmussen H., Seinre E., Thomas S., "Application of sensitivity analysis in design of sustainable buildings," Renewable Energy, vol. 34, no. 9, pp. 2030-2036, 2009.

[12] Tian W., "A review of sensitivity analysis methods in building energy analysis," Renewable and Sustainable Energy Reviews, vol. 20, pp. 411-419, 2013.

[13] Lam J. C. and Hui S., "Sensitivity analysis of energy performance of office buildings," Building and Environment, vol. 31, no. 1, pp. 27-39, 1996.

[14] Tavares P. F. de A. F. and Martins A. M. de O. G., "Energy efficient building design using sensitivity analysis-A case study," Energy and Buildings, vol. 39, no. 1, pp. 23-31, 2007.

[15] Suganthi L. and Samuel A. A., "Energy models for demand forecasting—A review," Renewable and Sustainable Energy Reviews, vol. 16, no. 2, pp. 1223-1240, 2012.

[16] Aydinalp M., Ugursal V., and Fung A., "Modelling of residential energy consumption at the national level," International Journal of Energy Research, vol. 27, no. 4, pp. 441-453, 2003.

[17] Huang J., Akbari H., Rainer L., Ritschard R., 481 Prototypical Commercial Buildings for 20 Urban Market Areas. US Department of Commerce, National Technical Information Service, 1991.

[18] Jones P., Lannon S., and Williams J., "Modelling building energy use at urban scale," In: Proc.7th International IBSPA Conference, Rio de Janeiro, Brazil, August, 2001, pp. 1683-1697.

[19] Clarke J. et al., "Simulation support for the formulation of domestic sector upgrading strategies," In: Proc. 8th International IBPSA conference, 2003, pp. 219-226.

[20] Kavgic M., Mavrogianni A., Mumovic D., Summerfield A., Stevanovic Z., and Djurovic-Petrovic M., "A review of bottom-up building stock models for energy consumption in the residential sector," Building and Environment, vol. 45, no. 7, pp. 16831697, 2010.

[21] Yamaguchi Y., Shimoda Y., and Mizuno M., "Proposal of a modeling approach considering urban form for evaluation of city level energy management," Energy and Buildings, vol. 39, no. 5, pp. 580-592, 2007.

[22] Shorrock L. and Dunster J., "The physically-based model BREHOMES and its use in deriving scenarios for the energy use and carbon dioxide emissions of the UK housing stock," Energy Policy, vol. 25, no. 12, pp. 1027-1037, 1997.

[23] Kolokotroni M., Giannitsaris I., and Watkins R., "The effect of the London urban heat island on building summer cooling demand and night ventilation strategies," Solar Energy, vol. 80, no. 4, pp. 383-392, 2006.

[24] A. Bruhns, G. Deurveilher, and J.-S. Roy, "A non linear regression model for mid-term load forecasting and improvements in seasonality," In: Proc. the 15th Power Systems Computation Conference, 2005, pp. 22-26.

[25] Amjady N., "Short-term hourly load forecasting using time-series modeling with peak load estimation capability," IEEE Transactions on Power Systems, vol. 16, no. 3, pp. 498-505, 2001.

[26] Amjady D. C. Park, M. El-Sharkawi, Marks R., Atlas L., Damborg M. and others, "Electric load forecasting using an artificial neural network," IEEE Transactions on Power Systems, vol. 6, no. 2, pp. 442-449, 1991.

[27] Lu C. N., Wu H. T., and Vemuri S. Vemuri, "Neural network based short term load forecasting," IEEE Transactions on Power Systems, vol. 8, no. 1, pp. 336-342, 1993.

[28] Chow T. and Leung C., "Neural network based short-term load forecasting using weather compensation," IEEE Transactions on Power Systems, vol. 11, no. 4, pp. 1736-1742, 1996. 
[29] Mandal P., Senjyu T. Senjyu, and Funabashi T., "Neural networks approach to forecast several hour ahead electricity prices and loads in deregulated market," Energy Conversion and Management, vol. 47, no. 15, pp. 2128-2142, 2006.

[30] Taylor J. W., Menezes L. M. de, and McSharry P. E., “A comparison of univariate methods for forecasting electricity demand up to a day ahead," International Journal of Forecasting, vol. 22, no. 1, pp. 1-16, 2006.

[31] Bianco V., Manca O., and Nardini S., "Electricity consumption forecasting in Italy using linear regression models," Energy, vol. 34, no. 9, pp. 1413-1421, 2009.

[32] Afshari A. and Friedrich L., "Mid-term Forecasting of Abu-Dhabi's Electrical Energy Consumption-Application to DemandSide Management Measurement \& Verification," In: Proc. EIC Climate Change Technology Conference, 2013.

[33] SCAD, "Statistical Yearbook of Abu Dhabi 2011," no. 2011, 2011.

[34] W. H. Greene, Econometric Analysis. 2003.

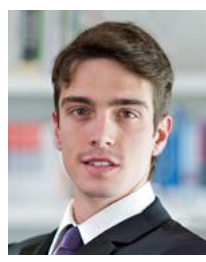

Luiz Friedrich is currently research engineer at the Department of Engineering Systems and Management at Masdar Insitute of Science and Technology (MIST), Abu Dhabi-UAE. His research focuses on modeling, analyzing and optimizing large-scale urban energy systems, assessing different demand side management measures towards efficient energy and infrastructure usage and decision support tools for policy making. Part of the International Renewable Energy Agency (IRENA) Scholarship Program, is engaged with different government entities in energy efficiency trials and studies.

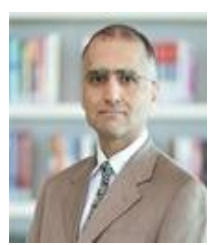

Dr. Afshin Afshari is currently Professor of Practice at Masdar Institute of Science and Technology where he is involved in a number of sponsored R\&D projects. His research interests encompass urban energy modeling-in particular the heat island effect--both for off-line energy management decision support and for on-line operational applications such as predictive control, load forecasting and fault detection/diagnosis. He is also interested in improving the energy efficiency of existing buildings through the design and verification of demand-side management programs. 